\title{
AN ANALYSIS OF RECENT DEVELOPMENTS IN SHEET MOULDING COMPOUND COMPOSITES AND THEIR MECHANICAL PERFORMANCE
}

\section{T. DHANUJAY SINGH ${ }^{1} \&$ M. SASIKUMAR ${ }^{2}$}

${ }^{I}$ Research Scholar, School of Mechanical and Building Sciences (SMBS), VIT University, Chennai Campus, India

${ }^{2}$ Professor, School of Mechanical and Building Sciences (SMBS), VIT University, Chennai Campus, India

\begin{abstract}
For years, metals and their alloys are the primary sources for all types of general and structural applications. In other words, metals like Copper, Zinc, Aluminum, Cast Iron etc. dominated the world for centuries and got applications in fields like automotive components, aerospace engineering, sports and marine industries. But, as these metals and alloys are heavy in weight and also due to high manufacturing cost, the question of reducing the overall weight and cost of the structures without affecting the performance has raised and hence lightweight materials like plastics and composites have come into the picture. In this paper, Sheet molded compound composites have been reviewed in terms of characteristics, manufacturing, research challenges and way forward.
\end{abstract}

KEYWORDS: SMC, Resin, Fiber, Filler, Applications

Received: Mar 04, 2020; Accepted: Mar 24, 2020; Published: May 25, 2020; Paper Id.: IJMPERDJUN202069

\section{INTRODUCTION}

Composite materials are well known for their superior properties. The usage of components made of Sheet Moulding Compound (SMC) based FRP components is increasing due to repeatable quality and manufacturing flexibility. And also, this compound is suitably used for mass production with the lowest possible raw material cost. The engineering applications such as rail transport, automotive, chemical environment, electrical insulating applications, domestic applications such as household furniture, milk cans and pre-fabricated housing. Thorough knowledge of weathering resistance assessment is very essential before the selection of material to arrive at a feasible engineering solution with cost-effectiveness.

In the present era of Green House effects, the utilization of natural wood is restricted. In this scenario, Sheet Moulding Compound (SMC) Composites based FRP components are an alternative resource to replace conventional metallic and wood-based materials. The present research work is aimed at establishing the facts related to the durability aspects of various Sheet Moulding Compound based FRP components subjected to tensile and compression tests and exposed to the humid, base and acidic environments [1]

\section{Composite Material}

When two materials having different chemical or physical properties mixed together, it produces a new material with different properties from that of original parent material, which is a composite material. Fibers used in the SMC process can be of different lengths i.e, short, discontinuous or long. In general, the length of fiber for this process ranges between $25 \mathrm{~mm}$ to $50 \mathrm{~mm}$ and the volume fraction of fiber is up to $65 \%$. Even though the SMC process seems to be much easier than other manufacturing processes, it has taken a lot of time in developing the 
process. This method was initiated by Charles Fisk [2].

\section{Material for SMC}

Current research work and future scope of SMCs includes development of high strength SMC compounds with low density, which is a primary and major requirement in automotive industry, impact resistance properties, usage of different types of fibers like Carbon fibers in the areas of aviation, defense and addition of natural fibers etc. In this regard, the material used in SMC plays a vital role in achieving the required properties. The major constituents of SMC material are Resin, Fiber and Filler. Mechanical properties can vary by changing the composition of the matrix.

\section{Resin}

- This was utilized to shift strain among the strengthening fibers of composite material. Resins are glued to clasp the fibers together and safeguard the fibers from the environment.

- R. J. Silva Nieto et al [3], predicted a mold flow of SMC materials made of unsaturated polyester resin. It was observed that the moulding charge geometry related to the product shape is very much important in order to make products better. Products with a $10 \%$ variation in strength distribution were observed with the calculated charge.

- R. J. Silva Nieto et al [4], analysed the rheological characterization of UP resin SMC composites. In this study, hybrid reinforcement made of oil palm as well as the glass fibers was used. It was observed that, when empty fruit bunch of palm along with glass fibers were reinforced in $\mathrm{SMC}$ compounds with $\mathrm{CaCO}_{3}$ as filler material, the water absorption was $32 \%$ whereas with Aluminium Trioxide it was 30\%. These composites were tested for Izod Impact Strength. For $\mathrm{CaCO}_{3}$, it was $78 \mathrm{~J} / \mathrm{m}$ whereas for Aluminium Trioxide it was $82 \mathrm{~J} / \mathrm{m}$.

- D.E. Walrath and D.F. Adams [5], have done the Iosipescu Shear Test for SMC composites which are flexible and helpful technique to measure shear values of various kinds of substances. Using SMC- R50, The tensile strength was $122.7 \mathrm{Mpa}$ and shear modulus was $5.1 \mathrm{GPa}$.

- In another work, Xia Cao and L. James Lee [6] studied the curing of Vinyl ester resin at low temperatures that provides better corrosion resistance when compared with UP resins. Vinyl Ester resins was compliant to hightemperature procedures. It was observed that from the existence of filler at $150^{\circ} \mathrm{C}$, the volume compression can be below $1 \%$

- Using Aliphatic Polyester, M. Esfandeh and M. R. Ebrahimi [7] made Flexible SMC. This SMC was prepared with chopped fibers and $20 \%$ of Maleic Polycaprolactone by weight. When tested for properties and compared with unmodified sheet metal compound, there was an improvement of $20 \%$ in impact strength, $67 \%$ improvement in maximum flexural strain and $58 \%$ improvement in maximum tensile strain.

- Jue $\mathrm{Lu}$ et al [8], worked with the alternate resins to replace the petroleum-based resin. They developed thermosetting resin from bio-based soya bean oil that was used for making SMC composites. By weight, this SMC resin has approximately $50 \%$ of Soya bean oil along with glass conversion temperature that was in range of $100^{\circ} \mathrm{C}$ to $115^{\circ} \mathrm{C}$.

- In another work, Jue Lu and Richard P [9], prepared a thermoset resin made of Linseed oil, which can be employed in the production of SMC goods. During maturation, this resin achieved moulding viscosity quickly. 
Mechanical tests on these composites found to be good when compared with other resins made from oils like soya bean. It has a flexural strength of 100MP also flexural modulus of $2.8 \mathrm{GPa}$ that is greater than soya bean oil values.

- Lei Wang et al [10], studied the hydrothermal consequences on the components of good functioning epoxy clay nano composites made of SMC. Experiments were conducted on water absorption with neat epoxy and $2.5 \%$ nanocomposite epoxy by weight. It was observed that water uptake was higher after 30 days where the tensile strength decreased from 50MPa to $40 \mathrm{MPa}$

- J. Mussig et al [11], used a vegetable oil-based thermo set prepreg to produce SMC composites for exterior components. These components were tested in longitudinal as well as transversal directions for their mechanical properties. It was found that both Young's modulus as well as Tensile power are up by $20 \%$ with glass fiber as reinforcement whereas, with natural fiber, both the properties were less by $20-30 \%$.

- In another work, Lei Wang et al [12], prepared SMC composites with epoxy and nano clay and analysed them for mechanical properties with different concentrations of clay. It was observed that increase in clay concentration by 0 to 2 weight percentage, the tensile power raised from $46 \mathrm{MPa}$ to $56 \mathrm{MPa}$ and it then decreased to $52 \mathrm{MPa}$ with the $3 \%$ clay.

- In another work, Jue Lu and Richard P. Wool [13], made resin from Maleated Hydroxylated Soybean Oil (MHSO) and Maleated Acrylated Epoxidized Soybean Oil (MAESO) using styrene. This resin was used to prepare SMC composites. It was observed that the flexural power along with modulus of the polymers were different from 61 to $87 \mathrm{MPa}$ as well as 1.6 to $2.4 \mathrm{GPa}$, respectively. The tensile power and modulus different from 27 to $44 \mathrm{MPa}$ as well as 1.6 to $2.5 \mathrm{GPa}$, elongation at break were around $5 \%$.

- $\quad$ Vicki P. McConnell [14], prepared SMC with HexMC carbon fiber. 60\% of discontinuous carbon fiber was used to make SMC composites for automobiles with epoxy resin. It was observed that, depending on part thickness, using HexMC carbon fiber, a rapid cycle time of 5 minutes was observed.

- Dejan D et al [15], studied Petro based resins and regular resins and observed that both the resins are having comparable mechanical properties like tensile modulus, tensile power and flexural modulus. The tensile power of UP Resin is $5 \%$ higher than petroleum-based resin whereas tensile modulus is around $6 \%$, flexural strength is around $8 \%$ higher.

- T. S. Lundstrom and A. Holmgren [16], studied the gap dissolution while compression of SMC moulding. It was observed that the huge bubbles could be dispersed to the liquid resin while production, so, there is a possibility to generate parts with very less void content.

- In another work, Naheed Saba et al [17], worked on epoxy resin and natural fiber-reinforced composites and their applications. A modified SMC using glass fibre and kenaf fibre was prepared and examined for its mechanical components and it were noted that the flexural strength, flexural modulus, tensile power, Young's modulus are similar to GMT which is used for automobile applications like cars.

- In a study, A. Trauth et al [18], analyzed glass fiber SMC and elucidated a favourable loading rate relying along a important raise of greatest strength (64\% for charge region specimens and $73 \%$ for flow region specimens) and puncture energy (67\% for (charge region specimens and $64 \%$ for flow region specimens) for a novel two-step 
healing resin structure.

\section{Fiber}

- Purpose of fiber is to support the load and to give hardness, power, thermal firmness and other structural elements in the composites. Fiber orientation and distribution in SMC composites stands a significant part.

- In a study on the debility damage of SMC made of short fiber, S.S. Wang and E.S.M. Chim [19], observed that in rotational debility, on a macroscopic scale, the harm was seen to dispense relatively and consistently in the unsystematic short-fiber SMC composite. Techniques of the debility harm include everlasting beginning as well as development of several kinds of cracks from microscopic strain concentrators.

- In another work, R. N. Kumar et al [20], worked on fire-resistant SMC composites made of oil palm fiber and glass fiber and tested for its impact strength and water absorption. Composites made of void fruit bunch palm fiber with no fire retardant or filler (FC1) and empty fruit bunch palm fiber and glass fiber with no fire retardant or filler (FC2) are compared with Aluminium Trihydroxide Filler cum for retardant with void fruit bunch palm fiber along with glass fiber (FC3). The Izod impact strength of FC1 was $30 \mathrm{~J} / \mathrm{m}, \mathrm{FC} 2$ was $8 \mathrm{~J} / \mathrm{m}$ and FC3 was $82 \mathrm{~J} / \mathrm{m}$ whereas water absorption for $\mathrm{FC} 1, \mathrm{FC} 2$ and $\mathrm{FC} 3$ was nearly $8 \%, 4 \%$ and $3.5 \%$ respectively.

- Composites prepared of unsaturated polyester resin and other supplements strengthened using glass fibers arose as an alternative for steel automotive outer groups. For planar elements, the dispersion of fibers is quite related and their orientation is in the way of the flow [21].

- V. Feuillade et al [22], studied the relationship the surface quality and glass fiber sizing composition of body panels to understand the glass fiber characteristics, material flow and surface quality. High fiber hardness prior to impregnation (around $135 \mathrm{~mm}$ ) improvement was observed and the glass fiber dispersion throughout the moulding and a less styrene solubility of the sizing (around 50\%) decreases the inadequacy emergence.

- In another work, E. Comte et al [23], worked on void formation in SMC manufacturing in which the effect of glass fiber size was seemed to potentially reduce the degassing problems. It was observed that designing SMC with a degassed paste results in empty content depletion accompanied with a raise in SMC paste by 9 weight \%. The quantity of void in the unhealed mixture has been calculated and starts from 10 to $18 \%$, while utilizing a tabletop compounding tool, compared to nearly $6 \%$ in a manufacturing SMC.

- T. D. Hapuarachchi et al [24], studied the Fire Retardancy of SMC made of glass fiber and hemp fiber. When tested for properties, the results showed that natural fiber-reinforced SMC could challenge with present building substances in terms of fire behaviour. The peak heat let out worth for the fire retardant (FR) NF-SMC were 176 $\mathrm{kW} / \mathrm{m}^{2}$ conversely for a non-FRNF-SMC were $361 \mathrm{~kW} / \mathrm{m}^{2}$

- H. K. Patel et al [25], used hemp fiber instead of glass fiber in a sheet moulding compound. When hemp fiber was treated with $2 \%$ alkaline concentration and composites were made, an important enhancement of $60 \%$ to the tensile power compared with untreated mixtures was observed.

- In other work, Sujit Das [26] assessed the life cycle of carbon fiber-reinforced mixture substances. In his 
assessment, it was observed that life cycle energy savings up to $30 \%$ was observed while making SMC composites.

- In another work, Jens Wulfsberg et al [27], worked on the composites made of carbon fiber sheet moulding mixture and prepreg compression moulding which would be useful for the aerospace industry. The outcomes acquired in the result takes to the decision that the growth of the combination of SMC and pre-impregnated, orientated carbon fiber fabrics are favorable mentioning to an enhancement of machine-driven elements. When tested, the flexural modulus with $25 \%$ fiber was around $8000 \mathrm{~N} / \mathrm{mm}^{2}$ and with $50 \%$ fiber was $11000 \mathrm{~N} / \mathrm{mm}^{2}$.

- Gianni Nicolette et al [28], studied the mechanical features of advanced systematic intermittent carbon/epoxy mixtures. The aim was to investigate experimentally the degree of isotropy of the mechanical elements like power and elongation to rupture and stiffness. A material system composed of systematically related determittent carbon fiber strands in a polymer matrix after consolidation by the compression moulding was taken for the experiment. Material with carbon fiber (CF) $53 \%$ indicated the maximum tensile power of $189 \mathrm{MPa}$ to that of $185 \mathrm{MPa}$ of $\mathrm{CF}$ $57 \%$ material whereas the $\mathrm{CF} 57 \%$ substance indicated the maximum modulus of $36 \mathrm{GPa}$ to that of $34 \mathrm{GPa}$ of $\mathrm{CF}$ $53 \%$ material.

- Amir Asadi et al [29], studied the composites made of Basalt fiber as a cost effective alternative to the existing glass fiber SMC. 25\% glass fiber- epoxy and 25\% Basalt fiber epoxy were taken for comparison and it was located with the values of Impact power and Tensile power were comparable with each other. With glass fibre, it is $66 \times 10^{3} \mathrm{~J} / \mathrm{m}^{2}$ whereas with Basalt fiber it is nearly $62 \times 10^{3} \mathrm{~J} / \mathrm{m}^{2}$. Similarly, Tensile strength was around $58 \mathrm{MPa}$ and 53MPa, Flexural Strength was 102MPa and 105MPa for Glass fiber and Basalt fiber SMC respectively.

- Miriam I. Lautenschläger et al [30], prepared Sheet moulding compound with natural fiber and tested for their mechanical properties. For Flax SMC, the tensile strength was round 90MPa and Young's modulus was around $7 \mathrm{GPa}$.

- Anna Trauth et al [31], analyzed the influence of hybridization on mechanical elements of continuousdiscontinuous Sheet Moulding Compounds. The fusions SMC were combined in a one-shot compression moulding procedure. Hybridization of SMC improved the substance elements with an important raise in tensile $(+171 \%)$ and compressive $(+151 \%)$ modulus of elasticity and tensile power $(+204 \%)$.

- Zhangxing Chen et al [32], analysed the loss of sliced carbon fiber Sheet Molding Compound mixtures under uniaxial tensile loading using Computational estimation and investigational study.

- Haibin Tang et al [33], studied the consequence of Fiber Orientation dispersion on stable debility Life Diagram of sliced Carbon Fiber Chip-Reinforced SMC composites. The substance activity of sliced carbon fiber chipreinforced Sheet shaping Compound composite was experimented beneath both quasi-static as well as rotational exhaustion loading states. Quasi-static tensile and compressive power data was gathered, subsequently by sequences of exhaustion examinations beneath three distinct rotational loading states, i.e., Tension-Tension (T-T), Compression-Compression (C-C), and Tension-Compression (T-C). In both the quasi-static and exhaustion analysis, important scattering of the evaluating detail was noted that caused from the spatially changing fiber orientation in the substance. Hence, the fiber orientation dispersion is bound to have a modestly frail influence on the quasi-static compression and $\mathrm{C}-\mathrm{C}$ exhaustion loading than on the quasi-static tension, $\mathrm{T}-\mathrm{T}$, and $\mathrm{T}$ - $\mathrm{C}$ exhaustion 
loading.

\section{Filler}

- The aim for including filler is to decrease the entire expense, raise dimensional constant, and decrease the contraction throughout shaping.

- T.Watanabe and M.Yasuda [34] studied the impact of constituents on mechanical elements during fracture behaviour of the sheetmoulding compound. As the filler volume fraction increases from 0 to 0.4 , the matrix viscosity increased from 1 Pa.s to 19 Pa.s and Tensile modulus increased from 2.5GPa to 6.5 GPa.

- Loren D. Larson et al [35], prepared sheet moulding composites with SMC Glass Microspheres with less density as an substitute to the conventional Calcium Carbonate filler material. Modifying from criterion density $(1.8 \mathrm{~g} / \mathrm{cc})$ to less density $(1.3 \mathrm{~g} / \mathrm{cc})$, SMC resulted in an expense decrease. When tested for properties, Tensile power raised from 106Mpa to 108Mpa whereas flexural strength raised from 224MPa to 234MPa.

- R. N. Kumar et al [36], used Rice husk ash as an alternative filler in unsaturated polyester-based sheet moulding compounds. The main intention behind this experiment were to employ the white and black rice husk ash, that were found in huge amounts and which pose circumstances obstacles in rice-manufacturing regions. The examination indicated that black ash had profound consequence to raise the modulus of rupture, modulus of elasticity, also to decrease the thickness inflammation and water absorption. Modulus of Elasticity rose primarily, after reduction on raising the quantity of calcium carbonate from $728 \mathrm{MPa}$ to $960 \mathrm{MPa}$, though the white ash reduces the MOE value $960 \mathrm{MPa}$ to $850 \mathrm{MPa}$, black ash raises the identical appreciably 490MPa to $1400 \mathrm{MPa}$.

- D.N.Goswami et al [37], used Shellac as an alternate filler material for sheet moulding compound and examined them for its mechanical properties. Powder Shellac (10-30\%) was added to the SMC composites with glass content being 33-36\% and found that Tensile strength of Shellac (10\%) filled was $667.7 \mathrm{kgf} / \mathrm{cm}^{2}$ whereas with $30 \%$ shellac it was $298 \mathrm{kgf} / \mathrm{cm}^{2}$.

- Hamid G. Kia [38], worked on the development of SMC for low moisture absorption. A diversity of polyester resins, low profile additives, and fillers has been revealed to excessive wetness, described as $90 \%$ relative wetness at $40{ }^{\circ} \mathrm{C}$, for elaborated hours. It had noted that Calcium Carbonate, the most usual filler for SMC, at a $0.12 \mathrm{wt} \%$ moisture absorption level, is the second-lessest in moisture absorption.

- Horatiu Teodorescu Draghicescu and Sorin Vlase [39], worked on Homogenization and averaging techniques to estimate elastic elements of pre-impregnated composite substances. To reduce the contraction throughout heal of a SMC prepreg, filler haas to be included in order to enhance the flow abilities.

- S Sathiyamurthy et al [40], studied the Calcium Carbonate impregnated short coir fiber-strengthened polyester composites for its mechanical behaviour. In this, the tensile, flexural, and influence activities of calcium carbonate-impregnated coir fiber-strengthened polyester composites was calculated. The short unconsidered coir fibers using distinct measurements of length, diameter, and filler content are utilized as reinforcements in polymer-based matrices. With fiber length of $10 \mathrm{~mm}$ and $4 \%$ filler, the tensile strength of $0.1 \mathrm{~mm}$ diameter fiber increased from $11.3 \mathrm{Mpa}$ to $13.3 \mathrm{Mpa}$ with a $0.18 \mathrm{~mm}$ diameter and flexural strength \& impact strength were 
increased from $21 \mathrm{Mpa}$ to $23.7 \mathrm{Mpa}$ and $31 \mathrm{~kJ} / \mathrm{m}^{2}$ to $33.2 \mathrm{~kJ} / \mathrm{m}^{2}$ for $0.1 \mathrm{~mm}$ diameter and $0.18 \mathrm{~mm}$ diameter fibre respectively.

- Julien Kiehl et al [41], analyzed the effect of filler material content on the viscosity of UP resin as well as Calcium Carbonate blend. It was investigated that for calcium carbonate contents ranging from 0 to $60 \mathrm{wt} \%$ with an average particle size of 5 microns, a rise of viscosity was noted with $\mathrm{CaCO}_{3}$ content.

- L. Savage [42], in his work, examined the potential offered by bio-derived fibers, wood and crop-derived particulates, and bio-resins as precursors in SMC for weight saving and sustainability. In this work, $\mathrm{CaCO}_{3}$ was replaced with bio-derived particulate filler. For a standard resin matrix $100 \%$ filler reinforced with Corn/wood flour, it was found that flexural strength stands as $166.5 \mathrm{Mpa}$ and flexural Modulus as $9.5 \mathrm{GPa}$. Similarly, for Standard resin matrix, 100\% filler reinforced with Cornflour, the flexural Strength was $197 \mathrm{MPa}$ and flex Modulus was 10.3GPa compared with 164MPa and 10.8GPa for that of a standard SMC. Also, Impact Resistance (Charpy) was found to be $91 \mathrm{~kJ} / \mathrm{m}^{2}, 74 \mathrm{~kJ} / \mathrm{m}^{2}$ and $60 \mathrm{~kJ} / \mathrm{m}^{2}$ for corn/wood, corn and standard SMC respectively.

- Y. J. Lee et al [43], examined the consequence of $\mathrm{CaCO}_{3}$ filler size on its technical elements. Flexural strength with respect to the mean particle size of $\mathrm{CaCO}_{3}$ in micrometer was examined. For particle size range of 2 micrometers to 5 micrometers, the flexural strength increased from $2 \mathrm{MPa}$ to $32 \mathrm{MPa}$ and then it reduced to $22 \mathrm{MPa}$ for 10 micrometers and $19 \mathrm{MPa}$ for 18 micrometers.

- Amir Asadi et al, studied lightweight Sheet Molding Compound (SMC) composites containing cellulose nanocrystals (CNC). The establishment of 1 and $1.5 \mathrm{wt} \% \mathrm{CNC}$ by distributing in the epoxy matrix of short GF/epoxy SMC mixtures with $25 \mathrm{wt} \%$ GF content (25GF/CNC-epoxy) generated $7.5 \%$ lighter mixtures with the identical tensile and flexural elements of 35GF/epoxy mixtures with no CNC. The inclusion of $1 \mathrm{wt} \% \mathrm{CNC}$ in $25 \mathrm{GF} / \mathrm{CNC}$-epoxy SMC mixtures lead to increase of $15 \%$ in elastic modulus, $11 \%$ in flexural modulus and $14 \%$ in flexural power, reaching the signifying elements of 35GF/ epoxy SMC mixtures. Though, it was located that the inclusion of CNC do not modify the influence energy, eliminating $10 \mathrm{wt} \%$ GF caused in a decrease of influence energy [44-45]

- Kadir Cavdar and Mahmut Bingo investigated the composites made of Basalt particle filled SMC composites. The length of the fiber used was $65 \mathrm{~mm}$. Composites of both $\mathrm{CaCO}_{3}$ and Basalt particle mixtures has been evaluated for technical elements. The tensile as well as flexural powers of composite materials were $67.58 \mathrm{~N} / \mathrm{mm}^{2}$ and $153.49 \mathrm{~N} / \mathrm{mm}^{2}$ for $\mathrm{CaCO}_{3}$ filler whereas $77.98 \mathrm{~N} / \mathrm{mm}^{2}$ and $165.93 \mathrm{~N} / \mathrm{mm}^{2}$ for Basalt filler [46]

\section{Applications}

- There are various applications of SMC composites. Few applications include Hood, Decklid, Fender, Front, Rear door and Roof. SMC compression shaping is an influential fabrication device, efficient of producing structural element for much more forceful applications. The most evolved high-speed procedure for structural composite elements is the compression shaping of SMC form substances [47].

- P. Beardmore and C. F. Johnson [48], discussed the capability for Composites in Structural Automotive Applications. The financial restrictions in a major manufacturing sector like automotive sectors are quite distinct from those of the aerospace or even the specialty vehicle sectors. Typically, SMC substances were employed for 
grill opening groups on number of car lines and closure groups (hoods, deck lids, doors) in a hard manner with particular techniques. A sliced glass fiber mixture, by contrast, may have an exhaustion restricted nearly to $25 \%$ of the ultimate power and would display much higher spread in elements.

- B. Sadasivam and P.K. Mallick [49], studied influence harm resistance of unsystematic fibre strengthened automotive composites. Low-energy effect features of four distinct unsystematic E-glass fiber strengthened thermoplastic and thermosetting matrix composites were analyzed. The low-energy effect leads to a dent on the impacted side and surface cracks on the unimpacted side of all four composites. The effect energy range was $15-$ $52 \mathrm{~J}$ for SMC-R50 which contains fiber $50 \%$ by weight and $\mathrm{CaCO}_{3}$ as filler.

- Mauricio Cabrera Rios and Jose M. Castro [50], worked on a financial mode of utilizing carbon fibers in Sheet Moulding Compound Compression moulding for automotive applications. It was noted that 4 ply glass cover has a flexural strength of $20 \mathrm{MPa}$ whereas 3 ply glass and 1 ply carbon laminate had $25 \mathrm{MPa}$.

- Geeta Mehta et al [51], prepared Big Blue Stem Grass (BBSG) bio-composite as an alternative to conventional glass fiber. Nowadays, many products are being manufactured using bio-based SMC from hockey sticks to cars. It was observed that the tensile power of Silane considered BBSG bio-composite is $29 \%$ higher than the power of unconsidered jute hemp (20 wt \%) and hybrid bio-composite is 35\% more than unconsidered BBSG biocomposite. The power of sliced E-glass composite is 170\% more than unconsidered Big Blue Stem Grass (BBSG) bio-composite

- James Holbert and Dan Houston [52], discussed applications of SMC products with UP resin in the automotive industry. Flexural Strength of $80 \mathrm{MPa}$ and $70 \mathrm{MPa}$ for Glass fiber of 30 Weight $\%$ and natural fiber of 35 weight $\%$ were observed whereas and Flexural Modulus was 6 GPa for both glass with and natural fiber with the above composition. Reprocessing carbon fibers from aerospace composite scrap have environmental and business advantages. The transfer from pilot scale to manufacturing functions is developing. Microwave-based reprocessing of non-upgraded fibers outcomes in reprocess which could be utilized in SMC compounds for new product applications [53].

- Robert A et al [54], discussed life cycle costs also the situational operation of less weight substances in automobile applications where SMC is one of the very usual composite substances utilized in the automotive sector. SMC has ability to endure paint baking temperatures and generate better standard surface complete creating the material specifically interesting to the automotive sector. There is a decrease of $57 \%$ weight utilizing the SMC compound weighing $2.5 \mathrm{~kg}$.

- $\quad$ M. Fette et al [55], discussed Automated and price beneficial manufacture of Hybrid Sheet Moulding Compound Aircraft elements. It was observed that benefits of the SMC technology, compared to other technologies for manufacturing fiber-strengthened plastic components were less substance prices, the chance of a completely automated procedure, small producing durations, a high material usage of almost $95 \%$, the chance of complex three dimensional structures and the chance of functional combination of metallic elements.

- Florin [56], prepared Large Auto Body Parts using SMVC composites. It was observed that manufacturing is affected by distance and rapid fiber slicing section also the speed of the tape manufacturing unit SMC. 
- Brookbank et al [57], prepared Economical carbon and cellulosic sheet moulding compounds that might be utilized for semi- and non-structural applications. This has been noted that the flexural strength and flexural modulus of cheaper carbon fiber SMC (CFSMC) was $159 \mathrm{MPa}$ and $14 \mathrm{GPa}$ respectively and for Glass fiber SMC the flexural strength 220 and flexural modulus 10GPa.

- Changsoon Jang et al [58], prepared sheet designing compound cover structures for the manufacturing of less weight automotive body frame. These structures were produced from high power steel skin as well as sheet shaping compound center. A complete substance featured was completed so as to ascertain the attributes of their sole substances, higher power steel and SMC inclusion to this. The initial simulation analysis targeting to examine the strain area on clarified B-pillar goods has demonstrated that 4mm of MS-SMC gives the identical pressure area of $2.3 \mathrm{~mm}$ of steel, whereas allowing a substantial weight decrease found to be $35.9 \%$.

- A F.Johnson [59], reviewed the mechanical attributes of SMC compounds and they were compared with GFRP materials generated by the traditional hand layup technique. Employing Vinyl ester automotive grade resin, Clay filler, after immersion in 5\% Sulphuric Acid, the flexural strength retention observed was $93.7 \%$ after 6 months, $74.0 \%$ after 1 year and $62.1 \%$ after 2 years.

- T.H. Le et al [60], analysed the fibrous microstructure of SMC mixtures. In this experiment, SMC continuous sheets were made from nearly $25 \mathrm{wt} \%$ sliced fiber-bundle mats implanted in a thick thermoset matrix critically created of mineral fillers ( $45 \mathrm{wt} \%$ ofCaCO 3 ), polyester resin ( $25 \mathrm{wt} \%$ ) also other additives( $5 \mathrm{wt} \%$ ) with fiber length $10-50 \mathrm{~mm}$. These parts were employed by the car sector to generate price benefit less weight and large body groups.

- Joakim Petterson and Peter Nilsson [61], studied the reprocessing of SMC in Standard Process Equipment. Reprocessing of SMC was simulated by including reground SMC scrap into fresh goods. Analysis indicated that the reground substances can be induced into fresh SMC utilizing consistent procedure tool along with small alterations in the formulations. Enhanced flexural power, together with a little decreased flexural modulus, were accomplished for SMC consisting 10\% reground substance. Flexural modulus of $87 \%$ and $96 \%$ of impact strength and $116 \%$ of flexural strengths were obtained with that of the original SMC test specimen.

- Takashi Inoh et al [62], used the discarded SMC that is ground to better particles and initiated to pure SMC as filler. The mechanized attributes of reprocessed SMC were identical to those of the initial substance it has been noted that the compound for the common application could be substituted with ground substance to a maximum of $20 \%$ by weight. With less failure of power and attributes compared to the consistent substance, it has been noted that tensile power were approximately $98 \%$ and flexural strength was $102 \%$ of the original material used.

- Hamid G. Kia[63], designed a maximum-pressure/high-temperature volumetric dilatometer for SMC composites. The tool could be functioned at temperatures as high as $250^{\circ} \mathrm{C}$ and pressures as high as $14 \mathrm{MPa}$. The result elucidates why, in common, there was a vast volume extension along with contraction related using heal of SMC. The entire volume varies in the dilatometer as the test has been healed was noted. As the curing time reaches 250 seconds, the volume expansion increased to 3 cubic centimeters and then got reduced to $1.5 \mathrm{~cm}^{3}$ at 300 seconds and then increased gradually to $2 \mathrm{~cm}^{3}$ in 600 seconds.

- Ki-Taek Kim and Yong-Taek Im [64], investigated attributes of compression-molded SMC components beneath 
plane stress state. The greater power values have been acquired from the path parallel to the substance flow management. The most surface roughness cost have acquired where greater design temperature and ending speed have been utilized. Impact of different shaping conditions on tensile attributes acquired from pressure specimen from the thickness of $3 \mathrm{~mm}$. Tensile strength at yield with $130{ }^{\circ} \mathrm{C}$ temperature and $15 \mathrm{~mm} / \mathrm{min}$ speed for $0^{0}$ (direction) was $35.75 \mathrm{MPa}$ and for $90^{\circ}$ direction was $61.45 \mathrm{MPa}$ whereas tensile strength at break was $52.41 \mathrm{MPa}$ and 26.12MPa for $0^{\circ}$ and $90^{\circ}$.

- Ki-Taek Kim et al [65], carried out an experimental study to ascertain the impacts of shaping variables on the physical and mechanical attributes of compression-shaped SMC. The flexural properties acquired from the threepoint curving examinations utilizing the compression-shaped plaques of the two distinct thicknesses of 3 and 7 $\mathrm{mm}$ under two distinct pattern temperatures $\left(130\right.$ and $\left.150^{\circ} \mathrm{C}\right)$ and pattern ending rates $(15$ and $45 \mathrm{~mm} / \mathrm{min})$ has been tested. The flexural powers have been in the scales of 105-187 MPa and 94-158 MPa for the 3 and the $7 \mathrm{~mm}$ thickness plaques.

- G. Camino et al [66], analysed SMC for its water aging property. The reference material observed was a convexshaped initial step of water sorption accompanied by a facilitation of sorption as well as higher uptake accompanied by a monotone raise of sorption up to equilibrium at $70^{\circ} \mathrm{C}$.

- Hamid G. Kia et al [67], investigated powder priming of sheet shaping compound groups. While covered with powder primer, reveal primer popping from the bake oven as a result of degassing of this substrate wetness. In the lack of wetness, yet it has been discovered that few SMCs revealed serious popping, though other SMC substances didn't. The evaluations demonstrated that air permeation to SMC at reduced temperatures accompanied by growth and degassing at high oven temperature was the procedure of collapse at the powder priming procedure for a few SMC substances. Spraying the powder primer on SMC groups which were heated to temperatures as high as $110^{\circ} \mathrm{C}$, have been discovered to get rid of the popping difficulty. This monitoring has been imputed to a decrease in micro voids of this less profile additive in high temperatures.

- In another work, Ryan Mills et al [68], explored the impact of hygrothermal aging on the dynamic mechanical attributes of SMC mixtures. Dry weight percent water uptake throughout aging, as a purpose of the square root of time, was observed. It was found to be 0.4 for $4 \mathrm{hrs}, 1.2$ for $12 \mathrm{hrs}, 1.4$ for $18 \mathrm{hrs}$ and 1.6 for $32 \mathrm{hrs}$ and as a function of time, 0.4 for $10 \mathrm{hrs}, 1.1$ for $200 \mathrm{hrs}$, around 1.4 near $350 \mathrm{hrs}$ and around 1.7 near $1100 \mathrm{hrs}$.

- Keiji Ogi and Masahiro Yamanouchi [69], investigated the temperature relied of estimating the flexural power of a carbon fiber-strengthened sheet shaping compound (CF-SMC). The predicted flexural powers were in sensibly fine contract with the analysis outcomes. Initially, fracture toughness increased a little bit and then decreases as the temperature increases. Fracture toughness was nearly $600 \mathrm{~J} / \mathrm{m}^{2}$ at $22^{\circ} \mathrm{C}$ increased to $262 \mathrm{~J} / \mathrm{m}^{2}$ at $45^{\circ} \mathrm{C}$ and then decreased to near $600 \mathrm{~J} / \mathrm{m}^{2}$ at $75^{\circ} \mathrm{C}$, below $600 \mathrm{~J} / \mathrm{m}^{2}$ at $90^{\circ} \mathrm{C}$ and decreased drastically to $400 \mathrm{~J} / \mathrm{m}^{2}$ near $110^{\circ} \mathrm{C}$.

\section{CONCLUSIONS}

A lot of research works have been carried out in recent decades in the field of Sheet Moulding Compound. Enhancements have appeared primarily because of elements such as enhanced fiber preference, extraction, treatment and Interfacial technology and composite procedure. This paper has reviewed the progress and was focused on different types of materials used in SMCs like Resin, Fiber, Filler and their impact on enhancing power, hardness and influence power involving the 
impact of wetness and weathering, along with various applications of SMCs in automotive. SMCs now compares favourably with another type of composites in terms of hardness and price, tensile and influence power. The lower densities for Natural Fiber SMCs cause to fine comparison for particular attributes. Applications of SMCs have expanded considerably involving load-bearing and outdoor applications like automotive exterior, underfloor groups, sports tool etc. Further study is still required to expand their application range consisting enhancement of flexural exhaustion, wetness resistance and other mechanical attributes. On whole, the expansion of SMC continuing at a higher rate and there seems to be a vastly bright favourable future ahead for their applications in all the fields of engineering.

\section{REFERENCES}

1. Laurent Orge, Sheet Molding Compounds.Nicolaisweoc223.tex V2 - 02/20/2012

2. Charles F. Fisk, Clifton, N. J. Process for increasing viscosity of uncured alkyd copolymer resinous mixtures and product, Application October 28, 1947, Serial No. 782,671

3. R. J. Silva Nieto, B. C. Fisher and A. W. Birley, Predicting mold flow for Unsaturated Polyester Resin Sheet Molding Compounds, Polymer Composites, September, 1980, Vol. No.1

4. R. J. Silva Nieto, B. C. Fisher and A. W. Birley, Rheological Characterization of Unsaturated Polyester Resin Sheet Molding Compound, Polymer Engg. and Science, June, 1981, Vol. 21, No. 8

5. D.E. Walrath and D.F. Adams, The Iosipescu Shear Test as Applied to Composite Materials, Experimental Mechanics 1983

6. Xia Cao, L. James Lee, Control of Shrinkage and Final Conversion of Vinyl Ester Resins Cured in Low-Temperature Molding Processes, Journal of Applied Polymer Science, Vol.90, 1486-1496(2003)

7. M. Esfandeh and M. R. Ebrahimi, Flexible Sheet Molding Compound (SMC) Using Aliphatic Polyester as Cross Linker, Hanser Publishers, Munich Intern. Polymer Processing XVIII (2003)

8. Jue Lu, Shrikant Khot, Richard P. Wool, New sheet molding compound resins from soybean oil Synthesis and characterization, Polymer 46 (2005) 71-80

9. Jue Lu, Richard P. Wool, Novel Thermosetting Resins for SMC Applications from Linseed Oil: Synthesis, characterization and properties, Journal of Applied Polymer Science, Vol. 99, 2481-2488(2006)

10. Lei Wang, Ke Wang, Ling Chen, Chaobin He, Hydrothermal Effects on the Thermo mechanical Properties of High Performance Epoxy/Clay, Polymer Engineering and Science-2006

11. J. Mussig, M. Schmehl, H.B. von Buttlar, U. Schonfeld, K. Arndt, Exterior components based on renewable resources produced with SMC technology -Considering a bus component as example, Industrial Crops and Products 24 (2006) 132-145

12. Lei Wang, Ke Wang, Ling Chen, Yongwei Zhang, He, Preparation, morphology and thermal / mechanical properties of epoxy/nanoclay composite, Composites: Part A 37(2006) 1890-1896

13. Jue Lu, Richard P. Wool, Sheet Molding Compound Resins From Soybean Oil: Thickening Behavior and Mechanical Properties, Polymer Engineering and Science-2007

14. Vicki P. McConnell, New recipes for SMC innovation, Reinforced Plastics, September 2008

15. Dejan D. Andjelkovic, Darcy A. Culkin, Roman Loza, Unsaturated Polyester Resins Derived from Renewable Resources, Composites \& Polycon 2009

16. T. S. Lundstrom, A. Holmgren, Dissolution of Voids during Compression Molding of SMC, Journal of Reinforced Plastics and Composites, Vol. 29, No. 12/2010 
17. Naheed Saba, Mohammad Jawaid, Othman Y Alothman, MT Paridah and Azman Hassan, Recent advances in epoxy resin, natural fiber-reinforced epoxy composites and their applications, Journal of Reinforced Plastics and Composites 0(0) 1-24, Dec-2015

18. A. Trauth, M. Bondy, K.A. Weidenmann, W. Altenhof, Mechanical properties and damage evolution of a structural sheet molding compound based on a novel two step curing resin system, Materials \& Design Volume 143, 5 April 2018, Pages 224237

19. S.S. Wang and E.S.M. Chim, Fatigue Damage and Degradation in Random Short-Fiber SMC Composite, Journal of Composite Materials, Vol. 17-March 1983

20. R. N. Kumar, L.M.Wei, H.D.Rozman and A.Abusamah, Fire Resistant Sheet Moulding Composites from Hybrid Reinforcements of Oil Palm-Fibres and Glass Fibre, International Journal of Polymeric Materials and Polymeric Biomaterials, vol.37, pp:43-52

21. V. Massardier-Nageotte, A. Maazouz, G. Peix, S. Bres, Methodologies for the characterisation of glass fibre orientation and distribution in large components moulded from sheet molding compounds (SMC), Polymer Testing 22 (2003) 867-873

22. V. Feuillade, A. Bergeret, J.C. Quantin, A. Crespy, Relationships between the glass fibre sizing composition and the surface quality of sheet moulding compounds (SMC) body panels, Composites Science and Technology 66 (2006) 115-127

23. E. Comte, D. Merhi, V. Michaud, J.A.E. Månson, Void Formation and Transport During SMC Manufacturing: Effect of the Glass Fiber Sizing, POLYMER COMPOSITES-2006

24. T. D. Hapuarachchi, G. Ren, M. Fan,P. J. Hogg, T. Peijs, Fire Retardancy of Natural Fibre Reinforced Sheet Moulding Compound, Appl Compos Mater (2007) 14:251-264

25. H. K. Patel,G. Ren,P. J. Hogg and T. Peijs, Hemp fibre as alternative to glass fibre in sheet moulding compound Part 1 influence of fibre content and surface treatment on mechanical properties, Plastics, Rubber and Composites 2010 Vol.39, No. 6

26. Sujit Das, Life cycle assessment of carbon fiber-reinforced polymer composites, Int J Life Cycle Assess (2011) 16:268-282

27. Jens Wulfsberg, Axel Herrmann, Gerhard Ziegmann, Georg Lonsdorfer, Nicole Stöß,Marc Fette, Combination of carbon fibre sheet moulding compound and prepreg compression moulding in aerospace industry, Procedia Engineering 81 ( 2014 ) 1601 1607

28. Gianni Nicoletto, Enrica Riva, Anellino Stocchi, Mechanical characterization of advanced random Discontinuous carbon/epoxy composites, Materials Today: Proceedings 3 ( 2016 ) 1079 - 1084

29. Amir Asadi, Ferdinand Baaij, Hendrik Mainka, Michael Rademacher, Jeffrey Thompson, Kyriaki Kalaitzidou, Basalt fibers as a sustainable and cost-effective alternative to glass fibers in sheet molding compound, Composites Part B: Engineering Volume 123, 15 August 2017, Pages 210-218

30. Miriam I. Lautenschläger, Lukas Mayer, Julian Gebauer, Kay A. Weidenmann, Frank Henning, Peter Elsner, Comparison of Filler-Dependent Mechanical Properties of Jute Fiber Reinforced Sheet and Bulk Molding Compound, Composite Structures, Volume 203, 1 November 2018, Pages 960-967

31. Anna Trauth, Kay André Weidenmann, Continuous-discontinuous Sheet Moulding Compounds - Effect of Hybridization on mechanical material properties, Composite Structures, Volume 202, 15 October 2018, Pages ;1087-1098

32. Zhangxing Chen, Haibin Tang, Yimin Shao, Qingping Sun, Guowei Zhou, Yang Li, Hongyi Xu, Danielle Zeng, Xuming Su, Failure of chopped carbon fiber Sheet Molding Compound (SMC) composites under uniaxial tensile loading: Computational 
prediction and experimental analysis, Composites Part A 118 (2019) 117-130

33. Haibin Tang, Zhangxing Chen, Guowei Zhou, Xuze Sun, Yang Li, Li Huang, Haiding Guo, Hongtae Kang, Danielle Zeng, Carlos Engler-Pinto, Xuming Su, Effect of Fiber Orientation Distribution on Constant Fatigue Life Diagram of Chopped Carbon Fiber Chip-Reinforced Sheet Molding Compound (SMC) Composite, International Journal of Fatigue, Volume 125, August 2019, Pages 394-405

34. T.Watanabe and M.Yasuda, Fracture behaviour of sheet moulding compounds Part 2. Influence of constituents on mechanical properties, Composites, January 1982

35. Loren D. Larson, Donald L. Robertson, Terry L. Ingham, Vinod C. Shah, Troy Botts and Russel D. Anderson, SMC Glass Microspheres as a Low-Density Alternative to Traditional Fillers, International Congress and Exposition Detroit, Michigan February 23-26, 1998

36. R. N. Kumar, Ban Hee Voon, H. D. Rozman, A.Abusamah and Frank Bauer, Rice husk ash as filler in unsaturated polyester based sheet moulding compounds (SMC), International Journal of Polymeric Materials, 53:659-670, 2004

37. D.N.Goswami, PC.Jha and K Mahato, Shellac as filler in sheet moulding compound, Indian Journal of Chemical Technology, Vol. 11, January 2004, pp.67-73

38. Hamid G. Kia, Development of Low Moisture Absorbing SMC, Journal of Composite Materials, Vol. 44, No. 1/2010

39. Horatiu Teodorescu-Draghicescu, Sorin Vlase, Homogenization and averaging methods to predict elastic properties of preimpregnated composite materials, Computational Materials Science 50 (2011) 1310-1314

40. S Sathiyamurthy, A Syed Abu Thaheer, and S Jayabal, Mechanical behaviours of calcium carbonate Impregnated short coir fibre-reinforced polyester composites,Proc.Mech E Vol. 226 Part L: J. Materials: Design and Applications

41. Julien Kiehl, Julien Huser, Sophie Bistac and Christelle Delaite, Influence of fillers content on the Viscosity of unsaturated polyester resin/calcium carbonate blends, Journal of Composite Materials 46(16) 1937-1942

42. L. Savage, Mouldable SMC/BMC automotive composites from sustainable resources, ECCM16 - $16^{\text {th }}$ European conference on composite materials, Seville, Spain, 22-26 June 2014

43. Y. J. Leea, Y. Kim, S. R. Kim, D. G. Shin, S.C. Ohe and W. T. Kwon, Size Effect of CaCO3 Filler on the Mechanical Properties of SMC Composites, Defect and Diffusion Forum, Vol. 365 (2015) pp 244-248

44. Amir Asadi, Mark Miller, Sanzida Sultana, Robert J. Moon, Kyriaki Kalaitzidou, Introducing cellulose nano crystals in sheet molding compounds (SMC), Composites: Part A 88 (2016) 206-215

45. Amir Asadi, Mark Miller, Arjun V. Singh, Robert J. Moon, Kyriaki Kalaitzidou, Lightweight sheet molding compound (SMC) composites containing cellulose nanocrystals, Composite Structures 160 (2017) 211-219

46. Kadir Cavdar and Mahmut Bingol, Investigation of Mechanical Properties of Basalt Particle-Filled SMC Composites, Hindawi Publishing Corporation International Journal of Polymer Science Volume 2016, Article ID:1231606, 6 pages

47. P. Beardmore, Composite Structures for Automobiles, Composite Structures 5 (1986) 163-176

48. P. Beardmore and C. F. Johnson, The Potential for Composites in Structural Automotive Applications, Composites Science and Technology 26 (1986) 251-281

49. B. Sadasivam and P.K. Mallick, Impact Damage Resistance of Random Fiber Reinforced Automotive Composites, Journal of Thermoplastic Composite Materials, Vol. 15-May 2002

50. Mauricio CabreraRıos and Jose M. Castro, An Economical Way of Using Carbon Fibers in Sheet Molding Compound 
Compression Molding for Automotive Applications, Polymer Composites-2006

51. Geeta Mehta, Amar K. Mohanty, Kelby Thayer, Manjusri Misra, and Lawrence T. Drzal, Novel Biocomposites Sheet Molding Compounds for Low Cost Housing Panel Applications, Journal of Polymers and the Environment, Vol. 13, No. 2, April 2005

52. James Holbery and Dan Houston, Natural-Fiber-Reinforced Polymer Composites in Automotive Applications, JOM November 2006

53. Vicki P. McConnell, Launching the carbon fibre recycling industry, Reinforcedplastics, 0034-3617/10, March/April 2010

54. Robert A. Witik, Jérôme Payet, Véronique Michaud, Christian Ludwig, Jan-Anders E. Månson, Assessing the life cycle costs and environmental performance of lightweight materials in automobile applications, Composites: Part A 42 (2011) 16941709

55. M. Fette, M. Hentschel, F. Köhler, J. Wulfsberg, A. Herrmann, Automated and cost-efficient Production of Hybrid Sheet Moulding Compound Aircraft Components, Procedia Manufacturing 6 (2016) 132 - 139

56. Teodorescu Draghicescu Florin, Opran Constantin Gheorghe, Sheet Moulding Compounds Of Large Auto Body Parts Made From Polymeric Composite, Applied Mechanics and Materials, Vol. 760, pp: 501-506

57. P Brookbank, L Savage and KE Evans, Economical carbon and cellulosic sheet moulding compounds for semi-and nonstructural applications, Journal of Reinforced Plastics and Composites 2015, Vol. 34(6) 437-453

58. Changsoon Jang, Luca Quagliato, Mohanraj Murugesan, Dongwook Kim, Cheolsoo Lee, Naksoo Kim, Material property of metal skin - sheet molding compound laminate structures for the production of lightweight vehicles body frame, Procedia Engineering 207 (2017) 878-883

59. A F.Johnson, Comparison of the mechanical properties of SMC with laminated GRP materials, Composites, Volume 17, No 3, July 1986

60. T.H. Le, P.J.J. Dumont, L. Orgeas, D. Favier, L. Salvo, E. Boller, X-ray phase contrast micro tomography for the analysis of the fibrous microstructure of SMC composites, Composites:Part A 39 (2008) 91-103

61. Joakim Petterson and Peter Nilsson, Recycling of SMC and BMC in Standard Process Equipment, Journal of Thermoplastic Composite Materials, J.ol. 7- January 1994

62. Takashi Inoh, Toshio Yokoi, Ken Ichi Sekiyama, Norihisa Kawamura and Yasuhiro Mishima, SMC Recycling Technology, Journal of Thermoplastic Composite Materials, Vol. 7, January 1994

63. Hamid G. Kia, High-Pressure/High-Temperature Dilatometry of SMC Low Profile Additives, Journal of Reinforced Plastics and Composites, Vol. 13-August 1994

64. Ki-Taek Kim and Yong-Taek Im, Experimental study on physical properties of compression molded SMC parts under plane strain condition, Composite Structures 35 (1996) 131-141

65. Ki-Taek Kim, Jin-Ho Jeong and Yong-Taek Im, Effect of molding parameters on compression molded sheet molding compounds parts, Journal of Materials Processing Tech. 67(1997),105-111

66. G. Camino, A. Ya. Polishchuk, M. P. Luda, M. Revellino, R. Blancon \& J. J. Martinez-Vega, Water ageing of SMC composite materials: a tool for material characterisation, Polwer Degradation and Srabilify 61 (1998) 53-63

67. Hamid G. Kia, Bhavesh Shah, Terrence J. Wathen and Harry A. Mitchell, Powder Priming of SMC. Part II: Failure Mechanism, Journal of Composite materials, Vol. 40, No. 16/2006

68. Ryan Mills, Douglas Gardner, Adriaan van Heiningen, Impact of hygrothermal aging on the dynamic mech. properties of 
Composites and their Mechanical Performance

Sheet Molding Compound, Journal of Materials Science 42(23):9822-9826 January 2007

69. Keiji Ogi and Masahiro Yamanouchi, Temperature Dependence of Flexural Strength of a CF-SMC Composite, Appl Compos Mater (2011) 18:397-408 
